\title{
Swimming activity of migrating Chinook salmon in a regulated river
}

\author{
Caleb T. Hasler ${ }^{1, *}$, Brent Mossop ${ }^{2}$, David A. Patterson ${ }^{3}$, Scott G. Hinch ${ }^{4}$, \\ Steve J. Cooke ${ }^{1}$

\begin{abstract}
${ }^{1}$ Fish Ecology and Conservation Physiology Laboratory, Department of Biology and Institute of Environmental Science, Carleton University, 1125 Colonel By Drive, Ottawa, Ontario K1S 5B6, Canada

${ }^{2}$ BC Hydro, 6911 Southpoint Drive, Burnaby, British Columbia V3N 4X8, Canada

${ }^{3}$ Fisheries and Oceans Canada, Science Branch, Pacific Region, Cooperative Resource Management Institute,
\end{abstract} \\ School of Resource and Environmental Management, Simon Fraser University, Burnaby, British Columbia V5A 1S6, Canada \\ ${ }^{4}$ Centre for Applied Conservation Research, Department of Forest Sciences, University of British Columbia, 2424 Main Mall, \\ Vancouver, British Columbia V6T 1Z4, Canada
}

\begin{abstract}
Adult Pacific salmon Oncorhynchus spp. have a fixed amount of energy available to fuel their freshwater spawning migration, so they must optimize their activity in a manner that conserves energy to ensure successful spawning. The flow regime in the Puntledge River in British Columbia, Canada, is regulated for hydropower production, and this has resulted in alterations in discharge and water temperature. The purpose of this study was to assess the relative changes to locomotory activity in Puntledge River summer-run Chinook salmon $O$. tshawytscha at varying discharges, temperatures, and reaches. Coded electromyogram (EMG) radio transmitters were used to evaluate aerobic swimming-muscle activity of free-swimming fish. Because transmitter calibration was not possible, a standardized EMG (SEMG) value was used to relate relative activity to variability among individuals, reaches, encountered temperatures, and discharge variables. A random forest algorithmic modeling analysis was used to account for the non-independence of predictor variables and activity values repeatedly recorded on the same fish. The model accounted for $57.6 \%$ of the variance in SEMG and revealed that individuals accounted for most of the variation in SEMG, followed by reach, temperature, and discharge. These findings indicate that individual variability in swimming strategies, migratory behaviors, and habitat use may influence swimming activity to a greater degree than river conditions. If such findings are confirmed in other regulated systems, this would have important implications for how alterations in flow and their biological consequences are evaluated.
\end{abstract}

KEY WORDS: Adult Pacific salmon · Upriver migration · Energy use · Electromyogram • EMG · Individual variation $\cdot$ Temperature $\cdot$ Discharge

Resale or republication not permitted without written consent of the publisher

\section{INTRODUCTION}

Most Pacific salmon Oncorhynchus spp. spend much of their lives in the ocean feeding and growing; however, once salmon begin migrating upstream, feeding ceases and energy not required for routine maintenance is used to fuel locomotory processes, mature the gonads, and spawn (reviewed by Brett 1995). Pacific salmon are semelparous, having only 1 opportunity to spawn, and once they initiate their homeward migration, they are committed to attempt spawning (Hinch et al. 2006). Pacific salmon typically utilize up to $50 \%$ of their stored total energy during migration (reviewed by Brett 1995, Hinch et al. 2006), and heightened migration activity can cause premature mortality due to energy exhaustion (Rand \& Hinch 1998, Macdonald 2000). Indeed, salmon that make long-distance upriver migrations allocate much 
more reserve energy to migratory activity and less to gonads (Crossin et al. 2004). Thus, fish should conserve energy by selecting migratory pathways that reduce energy use such as those with low water flow velocities (Liao 2007) or metabolically optimal temperatures (Farrell et al. 2008), and utilizing swimming behaviors that minimize energy expenditure such as swimming at metabolically optimal speeds (Hinch et al. 2006). Understanding habitat-specific activity is important for fisheries management because it may explain stock- and habitat-specific difficulties in salmon migrations (Ney 1993, Hinch et al. 1996, Hinch \& Rand 1998, Rand \& Hinch 1998). Given that large numbers of adult Pacific salmon often perish during upriver migrations (e.g. Cooke et al. 2004b, Keefer et al. 2008, Martins et al. 2011), such knowledge has the potential to clarify mechanisms associated with mortality and reduce management uncertainty.

Electromyogram (EMG) radio transmitters are biotelemetry devices (Cooke et al. 2004c) that measure changes to bioelectric voltages that are proportional to the degree and duration of muscle tension in free-swimming fish (Sullivan et al. 1963). These devices are increasingly being used to remotely assess habitat-specific activity, swimming speed, and energy expenditure in migratory salmonids (reviewed by Cooke et al. 2004a) and relate patterns in these variables to differences in river flows, bank configurations, water temperature, sex, size, and year (Hinch et al. 1996, 2002, Hinch \& Rand 1998, Hinch \& Bratty 2000, Standen et al. 2002, Brown et al. 2006, Hanson et al. 2008, Taylor et al. 2012). EMG telemetry has also been used to assess fish activity and energetics associated with salmonid movement in rivers affected by hydropower infrastructure, although the majority of studies that have used this technology focused on activity associated primarily with passage at fish ladders (e.g. Booth et al. 1997, Gowans et al. 2003, Brown et al. 2006, Scruton et al. 2007, Hasler et al. 2009). Few studies have used EMG technology to assess the activity or energetics of adult salmonids while migrating in hydropowerimpacted rivers (Cooke et al. 2004a).

The Puntledge River is a hydropower-impacted river located on Vancouver Island, British Columbia, Canada. Summer-run Chinook salmon Oncorhynchus tshawytscha migrate through this river en route to spawning grounds near the outlet of Comox Lake and in tributaries to Comox Lake. This run of Pacific salmon is of conservation concern (Trites et al. 1996, M. Sheng pers. comm.). Hydropower operations have resulted in alterations to flow and temperature that are evident during migratory periods and are thought to be responsible for declining trends in abundance (Holden 1958, Hirst 1991). The hydropower facility consists of a power-generating turbine located next to the river that uses diverted river water. This diversion results in a $7.2 \mathrm{~km}$ portion of the river having reduced flow and a swirling pool at the tailrace where the water is released back into the river. In addition, the reduced flows are particularly apparent at several natural structures (i.e. waterfalls, now equipped with blasted rock fish stairs) that may delay upstream migration of the adults. In particular, increased swimming activity through the hydropower-impacted sections of the river (the turbine release pool and the waterfalls) and other environmental variables (e.g. low river discharge and high temperature) may be negatively affecting migration.

The purpose of this study was to assess the changes in locomotory activity of Puntledge River summerrun Chinook salmon at varying discharges, temperatures, and reaches. We used coded EMG (CEMG) radio transmitters to evaluate aerobic swimmingmuscle activity of free-swimming fish and tested the hypothesis that locomotor activity levels would be influenced by environmental conditions. Specifically, we predicted that fish activity levels would be positively correlated with discharge and water temperature and would be highest in constricted reaches with complex flows. To quantify the influence of river reach, discharge, and temperature on the EMG telemetry-derived activity of the migrating salmon, we used an algorithmic modeling analysis (Breiman 2001) to understand the importance of each variable on relative changes to EMG values. This method also accounts for annual variation between data sets. Possible variation due to differences in swimming behaviors among the tagged fish (e.g. holding versus active movement patterns), and differences among individuals because of the use of non-calibrated EMG transmitters were also accounted for in the model.

\section{MATERIALS AND METHODS}

\section{Study site}

The Puntledge River extends from Comox Lake, is $16.9 \mathrm{~km}$ long and has a number of artificial and natural barriers to fish migration (Fig. 1). At river $\mathrm{km}$ (rkm) 13.3, a portion of the river's discharge is diverted by a diversion dam into a penstock and subsequently re-joins the river at rkm 6.8 (Fig. 1). Fish 
must pass the pool at the tailrace (Powerhouse Pool, PHP) before entering the Diversion Reach (Fig. 1). Reduced discharge at 2 major natural barriers (Stotan Falls and Nib Falls; Fig. 1) may affect the migration of summer-run Chinook and contribute to delay (Hasler et al. 2011). Each of the 2 barriers has 3 sets of blasted rock fish stairs. Summer-run Chinook salmon have been observed spawning between rkm 9.6 and rkm 16.9 (E. Guimond pers. comm.).

Hourly discharge $\left(\mathrm{m}^{3} \mathrm{~s}^{-1}\right)$ and water temperature $\left({ }^{\circ} \mathrm{C}\right)$ records at $\sim 12.5 \mathrm{rkm}$ were obtained from BC Hydro/Water Survey of Canada. Water temperature was also measured at the Lower Hatchery site using Stowaway Tidbit Temperature Loggers (Model TBI32-05+37; Onset Computer; temperature accuracy: $\pm 0.20^{\circ} \mathrm{C}$, temperature resolution: $\pm 0.16^{\circ} \mathrm{C}$ ). A finer temporal scale for flow and thermal data would have been desirable, but for the purpose of this study, we used hourly periods for all analyses (see 'CEMG data collection' for rationale for using hourly periods for CEMG data).

\section{River reaches}

For the purpose of this study, the river was divided into several zones (reaches, Fig. 1) based on habitat characteristics, known holding areas for tagged fish, and location in the river. Reach 1 (Lower Hatchery, $\mathrm{LH}$ ) is the location of the tagged-fish release site and is bound at the downstream end by a fence that crosses the river. This reach has mostly shallow cobble substrate with a $\sim 5 \mathrm{~m}$ deep pool of water near the north shore. Reach 2 (PHP) is a deep $(\sim 10 \mathrm{~m})$ swirling pool created by outflow of the penstock. Reach 3 (Island Pocket, ISP) has shallow riffles and small pools. Reach 4 is the $500 \mathrm{~m}$ stretch of river that includes the 3-tiered waterfall known as Stotan Falls (SF). Reach 5 (Highway zone, HW) has mostly shallow riffles and small pools. Reach 6 is the other 3-tiered waterfall, Nib Falls (NF). Reach 7 (Barber's Pool, $\mathrm{BP})$ is the farthest upstream reach in the study and has large deep pools. In terms of 'constrictiveness,' the SF and NF areas were the most constricted, as water flowed rapidly through the fish stairs. LH was constricted as well because of the addition of water from PHP. ISP, HW, and
BP were the least constricted of the areas. Habitat variables such as depth, wetted width (width of current flow), and bankfull width (maximum attainable stream width) were not recorded. For migratory behaviors through these reaches, see Hasler et al. (2011).

\section{Study animals}

Between 25 June and 20 July 2007 and 2008, 27 adult male summer-run Chinook salmon were diverted into raceways at the Lower Puntledge River Fish Hatchery for tagging (mean \pm SD total length: $759 \pm 81 \mathrm{~mm}$ in 2007, $\mathrm{n}=16 ; 647 \pm 60 \mathrm{~mm}$ in 2008, $\mathrm{n}=$ 11). Water temperature during tagging sessions was between 14 and $17^{\circ} \mathrm{C}$. Fish were housed in holding raceways filled with flowing river water for up to $7 \mathrm{~d}$. Fish used in this study were of natural origin and were attempting to move upstream. The serious conservation status of the stock meant that we were restricted to tagging only male fish. However, it should be noted that male Pacific salmon are typically less efficient and more variable with respect to energy use than females (Hinch \& Rand 1998). Furthermore, during longer-distance migration, there is some evidence that the disparity in energy use between sexes becomes less evident (Bernatchez \& Dodson 1987).

Fish were captured using dip nets and implanted with CEMG transmitters (CEMG2-R16-25 in 2007 and CEMG2-R11-25 in 2008; Lotek Engineering;

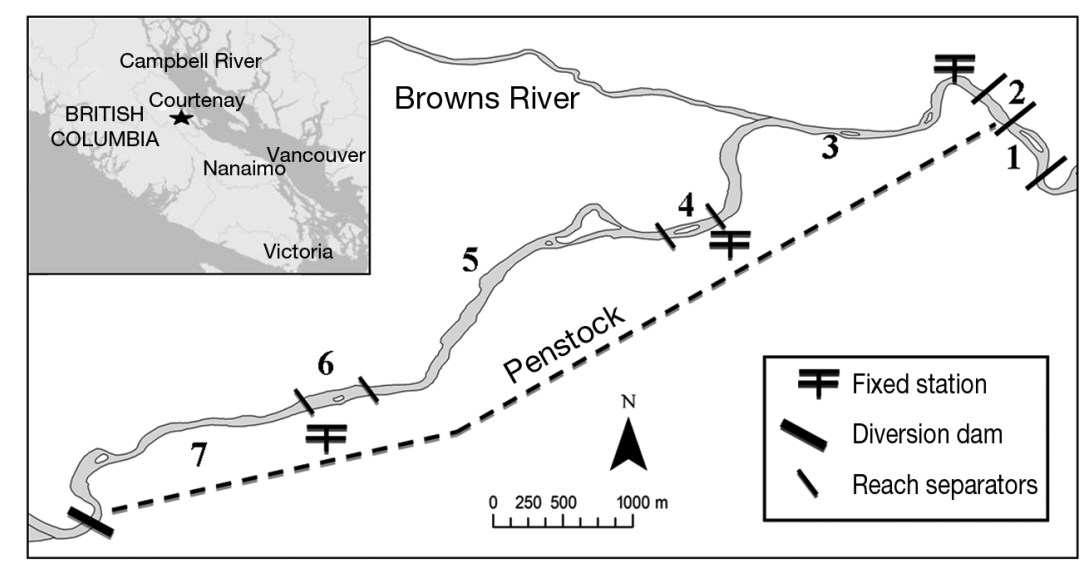

Fig. 1. Puntledge River, British Columbia, Canada (star in inset), and study site features. Reaches used in the study are shown as numbers: 1 (Lower Hatchery, LH), 2 (Powerhouse Pool, PHP), 3 (Island Pocket, ISP), 4 (Stotan Falls, SF), 5 (Highway, HW), 6 (Nib Falls, NF), 7 (Barber's Pool, BP). The stretch of the river from the diversion dam downstream to the penstock release at PHP is defined as Diversion Reach. Fixed stations: fixed antenna arrays for coded electromyogram detection. $\mathrm{rkm}=$ river $\mathrm{km}$ 
technology and surgical methods as outlined by Cooke et al. 2004a). Transmitters rendered muscle voltage change over a period of $2.5 \mathrm{~s}$, and the differences between the transmitters used in the 2 years were limited to physical size and battery life expectancy. Tags in 2007 had a larger diameter $(16 \mathrm{~mm})$ and longer battery life than tags used in 2008 $(11 \mathrm{~mm})$. Transmitters were cleaned with betadine and rinsed with distilled water prior to implantation. Fish were anesthetized with an induction solution of $40 \mathrm{ppm}$ clove oil and a maintenance bath of $30 \mathrm{ppm}$ clove oil (clove oil was emulsified in 95\% ethanol). A $50 \mathrm{~mm}$ incision to the right side of the ventral midline, posterior to the pelvic girdle, was then made and the transmitter was placed inside the body cavity. Gold tips of the electrodes $(14 \mathrm{~mm}$ in length) were then inserted into the axial musculature of the fish and positioned $10 \mathrm{~mm}$ apart. A 16gauge needle was used to puncture the body wall to allow for the antenna to exit. The incision was closed by 5 simple interrupted PDS-II absorbable sutures (3/0, sterile; Ethicon). Fish were then placed upright and held in the river (in a flow-through cage at the LH barrier) to recover for at least 30 min prior to release.

Fish were manually tracked from shore at least twice daily to estimate location (time to locate a tagged fish varied from $30 \mathrm{~s}$ to $15 \mathrm{~min}$ ) between June and September using a telemetry receiver (SRX-600 or SRX-400, Lotek Engineering) and a 3-element Yagi antenna. Fish were similarly tracked sporadically between September and October to determine possible spawning habitats and time of death. Fish locations (approximate rkm) were determined using 0 -point tracking, as the river is narrow with good access, meaning individual fish could be readily located. Zero-point tracking is a method whereby the tracker moves in the direction of the strongest signal while decreasing the gain until the signal is heard loudly at minimal gain. Positional tracking encompassed the time period that summer-run Chinook salmon enter the river through to post-spawning dieoff.

\section{CEMG data collection}

CEMG monitoring (using manual tracking and the fixed stations) was used until the first week of August. When fish were located twice a day using manual tracking, between June and early August, CEMG data were recorded for $10 \mathrm{~min}$. CEMG data were also collected from 3 fixed stations along the river and 1 mobile station. The 3 fixed stations were installed overlooking key holding areas: 1 overlooking PHP and ISP, 1 at SF, and 1 at NF (Fig. 1). Each was equipped with a telemetry receiver (SRX-600, Lotek Engineering), two 5-element Yagi antennas (1 pointing upstream at a $45^{\circ}$ angle, the other pointing downstream at a $45^{\circ}$ angle), one 3-element Yagi antenna (pointing orthogonally to the shoreline), a multi-antenna switching port (ASP_8, Lotek Engineering), and a $12 \mathrm{~V}$ battery. The equipment (with the exception of the antennas) was secured in a lock box to avoid tampering and theft. Another telemetry receiver and a single 3-element Yagi antenna were used as a mobile station that was deployed at sites frequented by tagged fish, but out of range of the other fixed stations, and was moved frequently.

CEMG values were summarized by calculating the hourly mode for each fish. A temporal scale of $1 \mathrm{~h}$ was used because of the receiver scanning settings chosen to adequately record CEMG values from each fish. The receiver scans through transmitter frequency, transmitter IDs and antennas, and records CEMG values for several seconds, resulting in non-continuous records of individuals. Modes were used because the data were non-parametric, and in theory, other calculations of central tendency may result in 'false' values (e.g. if a fish had CEMG values of only 10 and 20 during a particular hour, the mean would be 15, i.e. a CEMG value never measured by the sensor tag). Furthermore, because we were unable to calibrate the tags (Brown et al. 2007) due to limitations imposed on us by the conservation status of the stock and the long-term stock enhancement goals, standard EMG (SEMG) values were calculated to allow grouping of the data. SEMG is individual-specific and was determined by dividing the CEMG hourly modes of the fish by the 90th percentile for all CEMG data collected for the particular fish (all fish were bound by 0 minimum). This resulted in each CEMG mode being converted to an SEMG value between 0 and 1. SEMG values $>1$, which were rare $(<5 \%)$, were considered outliers and omitted from the analysis. Hours with $<10$ CEMG records fish $^{-1}$ were also omitted. This method resulted in each fish being measured on a similar scale and allowed us to group the SEMG values for each fish in order to understand relative differences in SEMG response to predictor variables (i.e. fish with high baseline CEMG could be grouped with fish with low baseline CEMG). An average of $176 \pm 2$ (SE) EMG readings $\mathrm{h}^{-1} \mathrm{fish}^{-1}$ was used in the analysis; thus each fish was being monitored for $>7$ min of every hour. 


\section{Data analysis}

A large set of correlated data (i.e. values were repeatedly measured in a short time interval on the same individuals) was collected and therefore the assumption of independence was violated. Yearly datasets were also grouped, again violating the assumption of independence. Our main focus was to quantify the possible relationships between the predictor variables (discharge, river reach, and temperature) and SEMG values. A random forests (RF) regression analysis was used to explore associations between the untransformed predictor variables and the response variable (Breiman 2001; further explained in the next paragraph). This type of analysis is robust to correlated data. Fish ID was also included in the analysis to control for individual variation in SEMGs. Individual variation in EMGs due to differences in tag performance (see Brown et al. 2007) should have been greatly reduced by our standardization procedure, assuming that all fish exhibited the same maximum and minimum range of muscle activity. However, we cannot assume that all of the variance in SEMGs accounted for by fish ID was due to variation in swimming performance and not due to heterogeneity in tag performance.

$\mathrm{RF}$ is a method for implementing stochastic determination and provides accurate predictions that do not over-fit the data by using bootstrapped samples to construct multiple trees (Breiman 2001, Prasad et al. 2006). The trees are constructed with a randomized subset of predictors (Breiman 2001, Prasad et al. 2006). The main model outputs are the percent of variance accounted for and estimates of predictor variable importance. The RF analysis was done using the 'randomForest' package in $\mathrm{R}$ (Liaw \& Wiener 2002, R Development Core Team 2010). The default setting was used for $m_{\text {try }}$ the number of predictor variables available for selection at each node $\left(m_{\text {try }}=2\right.$; the square root of the total number of predictor variables), and 1000 trees were generated. Partial dependence plots based on RF results were created to visually describe the relationship between the predictor variables and the SEMG hourly modes, independent of other predictor variables. Partial dependence plots yield a graphical depiction of the marginal effect of a variable on the response, thus the $y$-axis is only interpretable within variables and not across variables. The original RF analysis calculates biased estimates of importance for each predictor variable (Hothorn et al. 2006, Strobl et al. 2007, 2008). Thus, estimates of predictor variable importance were calculated using the RF of conditional inference trees developed in the 'party' package in R. These estimates represent the mean decrease in accuracy and are calculated by permuting each predictor variable separately and calculating the increase in misclassification rate. The most important variable is the one that, when omitted, degrades the model fit the most.

\section{RESULTS}

\section{Tagged fish}

CEMG values were collected for all tagged fish ( $\mathrm{n}=27$ ). Ninetieth percentiles ranged from 20 to 50 (Table A1 in the Appendix). Site-specific EMG output revealed variation in time spent in each reach (Table A1). EMG output was recorded for the most fish ( $\mathrm{n}=26)$ at ISP, but only 4 fish spent the majority of time there. Almost half of the fish (13) spent most of the time at SF, and in total, 24 fish were recorded near the area. Five fish spent the majority of time at PHP, and 15 fish had EMG output recorded at this site. Seventeen fish were recorded at NF, but only 4 fish spent considerable time there. No fish spent the majority of time at LH or BP, and 11 and 12 total fish, respectively, had EMG output associated with those reaches. In terms of total hours of EMG output records, irrespective of fish, most EMG output records were associated with $\mathrm{SF}_{\text {, }}$ PHP, and NF (Fig. 2).

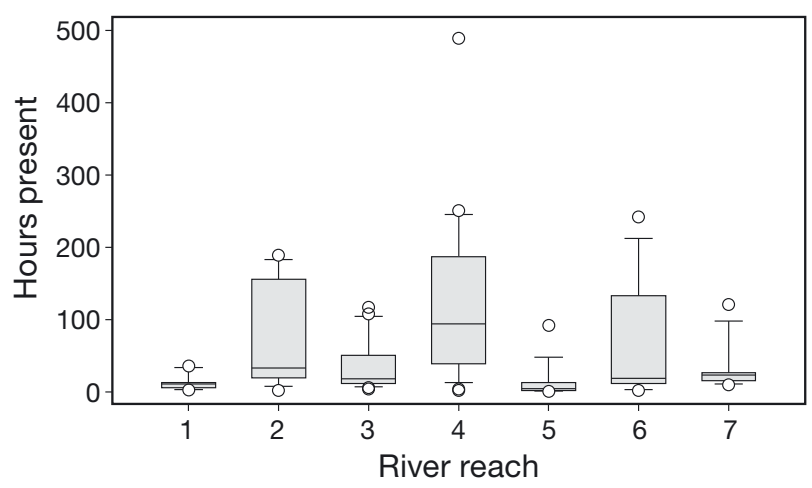

Fig. 2. Oncorhynchus tshawytscha. Number of hours fish spent at each of the river reaches used in the study: 1 (LH), 2 (PHP), 3 (ISP), 4 (SF), 5 (HW), 6 (NF), 7 (BP). Each data point is the length of time (h) a tagged fish spent at the location. Open circles represent outliers, whiskers represent minimum and maximum values, the box is bound by the upper and lower quartiles, and the bar within the box represents the median value. Reach abbreviations as in Fig. 1 


\section{Environmental variables}

Puntledge River discharge recorded at $\sim 12.5 \mathrm{rkm}$ during the study period ranged from 4 to $>16 \mathrm{~m}^{3} \mathrm{~s}^{-1}$ (maximum: $53 \mathrm{~m}^{3} \mathrm{~s}^{-1}$; Fig. 3). The distribution of discharge was binomial, with 2 peaks, between 6 and $8 \mathrm{~m}^{3} \mathrm{~s}^{-1}$ and between 12 and $14 \mathrm{~m}^{3} \mathrm{~s}^{-1}$ (Fig. 3a) representing the baseline flow ( 6 and $8 \mathrm{~m}^{3} \mathrm{~s}^{-1}$ ) and the heightened pulse flow used to influence upstream movement of salmon in the river (12 and $14 \mathrm{~m}^{3} \mathrm{~s}^{-1}$ ). Mean \pm SD temperature of the river during the study period was $17.4 \pm 1.4^{\circ} \mathrm{C}$ (Fig. 3b).

\section{RF Model}

RF analysis indicated that $57.6 \%$ of the variance in SEMG was accounted for by the predictors. A further conditional RF completed to assess the unbiased importance of each variable found that fish ID was the most important predictor, followed by reach,
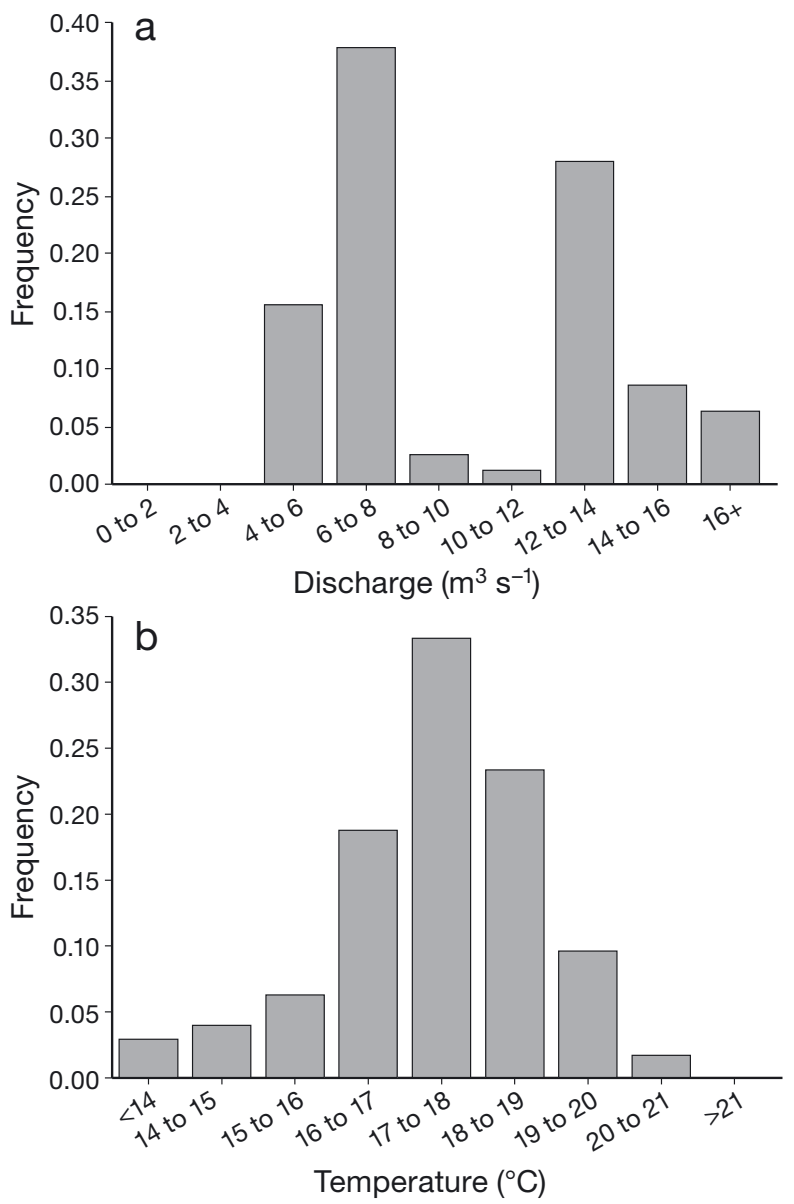

Fig. 3. (a) River discharge $\left(\mathrm{m}^{3} \mathrm{~s}^{-1}\right)$ and (b) river temperature $\left({ }^{\circ} \mathrm{C}\right)$ during the 2007 and 2008 study period
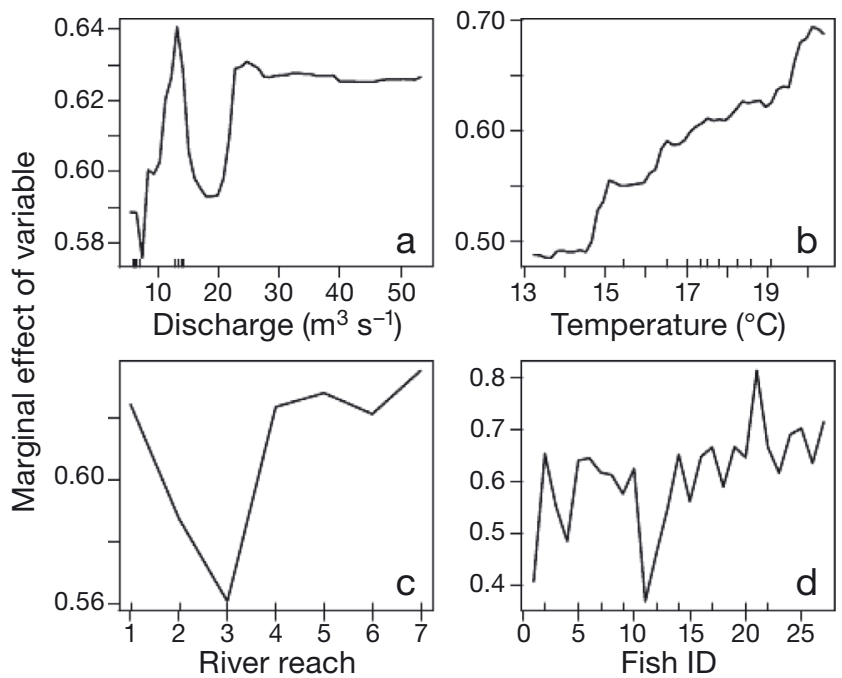

Fig. 4. Partial dependence plots depicting the marginal effect of each predictor variable on the standardized electromyogram. (a) River discharge, (b) temperature, (c) river reach (see Fig. 1), and (d) fish ID. The $y$-axes do not represent absolutes and are unitless

temperature, and flow. The importance values were $0.045,0.014,0.009$, and 0.007 , respectively, meaning that fish ID had the highest degradation effect when omitted from the model. The relationships shown in the partial dependence plots indicate that the marginal SEMG response due to fish ID varied by individual, with 3 fish $(1,4,11)$ showing lower SEMG than the other fish (Fig. 4d). Fish 21 had the highest SEMG values. Fish in the PHP and ISP reaches $(2$ and 3 in the plot; Fig. 4c) had lower SEMG values than the other reaches, and all other reaches yielded similar SEMG values. The relationships between river discharge and SMG and between temperature and SEMG were both generally positive (Fig. 4a,b).

\section{DISCUSSION}

Using CEMG radio transmitters implanted in freeswimming summer-run Chinook salmon in the Puntledge River, we tested the hypothesis that locomotor activity levels would be influenced by environmental conditions. Specifically, we predicted that fish activity would be positively correlated with discharge and water temperature and would be highest in constricted reaches with complex flows. Contrary to our predictions, our model, which accounted for $57.6 \%$ of the variance in SEMG, revealed that individuals accounted for most of the variation in SEMG. Environmental characteristics such as river reach, temperature, and discharge contributed comparatively little 
to the model. These findings may indicate that individual variability in swimming strategies, migratory behaviors, and habitat use influence activity to a greater degree than river environmental conditions such as flow and temperature. However, transmitter variability may also contribute to variation in activity, more so than river conditions.

The central importance of fish ID in accounting for SEMG activity levels was determined by applying an RF analysis (RF accounted for $>50 \%$ of the total variance in SEMG). This type of analysis has not previously been used with EMG data. It is possible that the greater importance of fish ID could have been due to the use of uncalibrated transmitters and transmitter variability. For example, a number of studies using calibrated EMG transmitters found significant variation among individuals (Hinch \& Bratty 2000, Hinch et al. 2002, Scruton et al. 2007, Pon et al. 2009). However, we attempted to standardize the data by individual so that transmitter variation had a minimal influence on EMG activity, therefore the differences observed are likely reflective of real biological variation. Indeed, this would be in accordance with a growing body of literature that demonstrates that individual variation in fish swimming ability is repeatable and statistically valid (e.g. Kolok 1999, Hanson et al. 2008, 2010). To put it more simply, individuals matter (Bennett 1987). In a similar study involving Fraser River sockeye salmon, individual fish accounted for significant amounts of variation in different types of swimming (i.e. time spent burst-swimming and sustained swimming speeds), and this may be due to difficulty in locating migration cues as the authors could find no evidence that individual traits such as sex and size had an effect (Hinch et al. 2002). Furthermore, a study by Hanson et al. (2008) revealed that upriver-migrating sockeye salmon swim at similar speeds in different reaches, which emphasizes the importance of individual variation. Hydropower infrastructure may also contribute to the individual variation observed, as EMGs obtained near facilities vary widely, perhaps as a result of turbulence and complex flows, and associated confusion for fish (Pon et al. 2009). Overall, our study further supports the contribution of individuality to estimates of activity in free-ranging fish.

Location (i.e. reach) of the tagged fish was the second most important variable in the RF analysis. Physical characteristics of fish locations cause variability in EMG-obtained activity estimates for salmonids (Standen et al. 2002, Scruton et al. 2007). For example, reach characteristic was the primary factor influencing activity levels in adult pink and sockeye salmon migrating through the Fraser River Canyon (Standen et al. 2002), as increased activity levels were found when fish were migrating through reaches that were constricted by islands and river bars. The partial dependence plots in our study suggest that higher SEMGs occurred in the constricted waterfalls locations, SF and $\mathrm{NF}_{\text {, when }}$ compared with less constricted reaches of the river pools, PHP and ISP. However, similar values to SF and NF were also measured at LH, HW, and BP (all less constricted reaches). Furthermore, a study on Atlantic salmon near a hydropower facility in Newfoundland (Scruton et al. 2007) and a separate study on Chinook salmon in the Columbia River (Brown et al. 2006) suggested that EMG activity is heightened near tailraces associated with hydropower facilities. Our study did not demonstrate higher activity at PHP, a reach with similar physical characteristics to the tailrace reach in the former studies.

In a relative sense, environmental conditions (i.e. temperature and river discharge) did not contribute much importance to the analysis. This is particular surprising for temperature, as it is the 'master factor' in fish physiological processes. Indeed, our partial dependence plot of temperature showed increased SEMG values at greater temperatures, but the importance of temperature was low. In our study, river temperature ranged from $\sim 14$ to $21.5^{\circ} \mathrm{C}$ with a mean of $\sim 17^{\circ} \mathrm{C}$. The available thermal habitat was at the higher end of the species-specific thermal preference (Brett 1995), but differences among stocks do exist (Farrell et al. 2008). Likewise, because fish inhabit fluvial environments, river discharge may influence activity patterns in fish. Our partial dependence plot of river discharge revealed a sharp increase in SEMG between low and moderate flows; however, the importance of river discharge was the smallest of the 4 variables examined.

Prior to initiating our study, we had hypothesized that the CEMG transmitters would detect increased activity caused by fish ascending the fish stairs at SF and NF given that a previous study had found Chinook salmon frequently exceed sustained swimming speeds while swimming over waterfalls (Brown et al. 2002). However, we did not observe heightened SEMG at the waterfalls. Detecting burst-swimming activity is difficult using CEMG transmitters because of the electrode placement in the red muscle instead of the white muscle, which is used during anaerobic swimming (Cooke et al. 2004a). Furthermore, the temporal scale used in this study may have been too coarse to detect increased SEMGs during waterfall ascent. In other words, waterfall ascents may have happened very quickly as, by definition, burstswimming occurs for very short time periods $(<20 \mathrm{~s})$ 
and thus were not detected with the receiver scanning cycles used in our study. Pon et al. (2009) found few incidences of burst-swimming during fish passage at a fish ladder, despite the fact that fish were in the ladder for extended time periods, emphasizing that detecting anaerobic burst activity with CEMG tags can be difficult.

Some of the tagged fish likely died during the study. Three fish had few hours $(<100 \mathrm{~h})$ of recorded CEMG, which may have been a result of the fish dying due to the tagging procedure, although no mortalities were found despite conducting snorkeling observations on these fish. Gowans et al. (2003) suggested that fungal infections can cause fish mortality in EMG studies, and may be especially relevant when fish inhabit water near the top of their preferred thermal range. In comparison with studies conducted on other salmonids, the tagged fish took longer to recover from surgery (C. T. Hasler \& S. J. Cooke unpubl. data). Data were processed in a manner that excluded CEMG values once fish mortality was suspected, thus it is unlikely that CEMG values from morbid fish biased the outcome of the analysis.

A limitation of this study was that we were unable to calibrate the CEMG transmitters once implanted into the fish. Brown et al. (2007) evaluated 20 CEMG transmitters implanted in rainbow trout and found a strong positive relationship between CEMG output and swimming speed, but the relationship weakened when data were grouped. This suggested that the transmitters behaved differently as a result of small differences in electronic components, so the authors suggested that each tag be calibrated to swimming speed separately to ensure accurate muscle activity estimates. Calibration of the transmitter typically involves prolonged handling and confinement of tagged fish, as well as forced swimming trials in either a swimming tunnel or a circular swim flume. This process is inherently stressful and may induce pre-spawn mortality (Geist et al. 2002, Standen et al. 2002, Cooke et al. 2004a). The Puntledge River summer-run Chinook salmon are of conservation concern, and the federal government has supported a hatchery on the river for over $35 \mathrm{yr}$ in an effort to increase the number of returning adults (D. Miller pers. comm.). Because of this effort, many fish are captured upon arrival at the hatchery and kept for enhancement purposes. The relatively invasive tagging procedures (for an imperiled stock) required to use CEMG transmitters (i.e. level 5 anesthesia and internal placement of electrodes and transmitters) are more stressful to the fish than conventional gastric tagging procedures (Cooke et al. 2004a). Our scien- tific collection permit did not allow for calibration due to risk from further handling, confinement, and exhaustion; our tags therefore remained uncalibrated. Nonetheless, all studies that have calibrated EMG tags have shown that CEMG output increases with increasing swimming speed (i.e. linear relationship between EMG and swimming or metabolic metrics). Therefore, relative increases in CEMG are a proxy for an increase in swimming speed and associated energetic costs. Although we limit our discussion to focus on relative changes in activity (not absolute energetic costs), our study determines the relative contribution of the variables most associated with hydropower management (controlled flow releases, temperature, and man-made migration barriers) in explaining the variation in swimming muscle activity.

A recent review has highlighted the importance of developing quantitative relationships between river flow and ecological responses (Poff \& Zimmerman 2010). Our study attempted to relate activity to environmental and habitat characteristics while also accounting for the 'subject effect.' The analysis also accounted for the non-independence of the sampling method, and this type of method is encouraged instead of the usual approach of comparing grouped means. Although we used uncalibrated CEMG transmitters, our study did account for environmental and habitat characteristics in the activity levels of fish in a hydropower river, but the observed relationships were moderate. Locomotor activity is likely influenced by numerous biotic and abiotic factors in hydropower systems. Our findings may indicate that individual variability in swimming strategies, migratory behaviors, and habitat use influence activity to a greater degree than river conditions. If such findings are confirmed in other regulated systems, it would have important implications for how alterations in flow and their biological consequences are evaluated. Moreover, our study highlights the importance of using inter-individual variation in future analyses of fish activity.

Acknowledgements. Funding and logistical support for this study were provided by the Natural Sciences and Engineering Research Council of Canada (NSERC), BC Hydro, Carleton University, University of British Columbia, and Fisheries and Oceans Canada. Special thanks to the field assistants and staff of the Puntledge River Hatchery. E. Guimond and E. Wichmann contributed significantly to the study design and implementation. N. Lapointe provided assistance with statistical analysis. The research and procedures carried out in this publication were conducted in accordance with the Animal Care Committee at Carleton University (Protocol No. B06-12), and fish were collected using a Fisheries and Oceans Collection Permit. 


\section{LITERATURE CITED}

Bennett AF (1987) Interindividual variability: an underutilized resource. In: Feder ME, Bennett AF, Burggren WW, Huey RB (eds) New directions in ecological physiology. Cambridge University Press, Cambridge, p 147-169

- Bernatchez L, Dodson JJ (1987) Relationship between bioenergetics and behaviour in anadromous fish migrations. Can J Fish Aquat Sci 44:399-407

Booth RK, McKinley RS, Økland F, Sisak MM (1997) In situ measurement of swimming performance of wild Atlantic salmon (Salmo salar) using radio transmitted electromyogram signals. Aquat Living Resour 10:213-219

Breiman L (2001) Random forests. Mach Learn 45:5-32

Brett JR (1995) Energetics. In: Groot C, Margolis L, Clarke WC (eds) Physiological ecology of Pacific salmon. University of British Columbia Press, Vancouver, BC, p 1-68

Brown RS, Geist DR (2002) Determination of swimming speeds and energetic demands of upriver migrating fall chinook salmon (Oncorhynchus tshawytscha) in the Klickitat River, Washington. Project 22063, Contract 42663A. Pacific Northwest Laboratory, Bonneville Power Administration, Richland, WA

> Brown RS, Geist DR, Mesa MG (2006) Use of electromyogram telemetry to assess swimming activity of adult spring Chinook salmon migrating past a Columbia River dam. Trans Am Fish Soc 135:281-287

Brown RS, Tatara CP, Stephenson JR, Berejikian BA (2007) Evaluation of a new coded electromyogram transmitter for studying swimming behaviour and energetics in fish. N Am J Fish Manag 27:765-772

> Cooke SJ, Thorstad E, Hinch SG (2004a) Activity and energetics of free-swimming fish: insights from electromyogram telemetry. Fish Fish 5:21-52

Cooke SJ, Hinch SG, Wikelski M, Andrews RD, Kuchel LJ, Wolcott TG, Butler PJ (2004b) Biotelemetry: a mechanistic approach to ecology. Trends Ecol Evol 19:334-343

Cooke SJ, Hinch SG, Farrell AP, Lapointe MF and others (2004c) Abnormal migration timing and high en route mortality of sockeye salmon in the Fraser River, British Columbia. Fisheries 29:22-33

Crossin GT, Hinch SG, Farrell AP, Higgs DA, Lotto AG, Oakes JD, Healey MC (2004) Energetics and morphology of sockeye salmon: effects of upriver migratory distance and elevation. J Fish Biol 65:788-810

Farrell AP, Hinch SG, Cooke SJ, Patterson DA, Crossin GT, Lapointe M, Mathes MT (2008) Pacific salmon in hot water: applying aerobic scope models and biotelemetry to predict the success of spawning migrations. Physiol Biochem Zool 81:697-708

Geist DR, Brown RS, Lepla K, Chandler J (2002) Practical application of electromyogram radiotelemetry: the suitability of applying laboratory acquired calibration data to field data. N Am J Fish Manag 22:474-479

Gowans ARD, Armstrong JD, Priede IG, Mckelvey S (2003) Movements of Atlantic salmon migrating upstream through a fish-pass complex in Scotland. Ecol Freshw Fish 12:177-189

> Hanson KC, Cooke SJ, Hinch SG, Crossin GT and others (2008) Individual variation in migration speed of up-river migrating sockeye salmon in the Fraser River in relation to their physiological and energetic status at marine approach. Physiol Biochem Zool 81:255-268

Hanson KC, Hasler CT, Donaldson MR, Cooke SJ (2010) Stability of swimming performance and activity hierarchies among wild largemouth bass (Micropterus salmoides) at multiple temporal scales: evidence for context- dependent shuffling between seasons. Can J Zool 88: 324-333

Hasler CT, Pon LB, Roscoe DW, Mossop B, Patterson DA, Hinch SG, Cooke SJ (2009) Expanding the 'toolbox' for studying the biological responses of individual fish to hydropower infrastructure and operating strategies. Environ Rev 17:179-197

- Hasler CT, Donaldson MR, Sunder RPB, Guimond E and others (2011) Osmoregulatory, metabolic, and nutritional condition of summer-run male Chinook salmon in relation to their fate and migratory behavior in a regulated river. Endang Species Res 14:79-89

- Hinch SG, Bratty J (2000) Effects of swim speed and activity pattern on success of adult sockeye salmon migration through an area of difficult passage. Trans Am Fish Soc 129:598-606

Hinch SG, Rand PS (1998) Swim speeds and energy use in upriver-migrating sockeye salmon (Oncorhynchus nerka): role of local environment and fish characteristics. Can J Fish Aquat Sci 55:1821-1831

Hinch SG, Diewert RE, Lissimore TJ, Prince AMJ, Healey MC, Henderson MA (1996) Use of electromyogram telemetry to assess difficult passage areas for rivermigrating adult sockeye salmon. Trans Am Fish Soc 125: $253-260$

Hinch SG, Standen EM, Healey MC, Farrell AP (2002) Swimming patterns and behaviour of upriver migrating adult pink (Oncorhynchus gorbuscha) and sockeye (O. nerka) salmon as assessed by EMG telemetry in the Fraser River, British Columbia. Hydrobiologia 483:147-160

Hinch SG, Cooke SJ, Healey MC, Farrell AP (2006) Behavioural physiology of fish migrations: salmon as a model approach. In: Sloman K, Balshine S, Wilson R (eds) Fish physiology, Vol 24: behaviour and physiology of fish. Academic Press, London, p 239-295

Hirst SM (1991) Impacts of the operation of existing hydroelectric developments of fishery resources in British Columbia, Vol 2. Inland fisheries. Can Manuscr Rep Fish Aquat Sci 2093. Department of Fisheries and Oceans, Vancouver, BC

Holden MJ (1958) A summary of the fisheries problems associated with the Puntledge River power development. Memo report. File 31-3-P1. Department of Fisheries, Vancouver

Hothorn T, Hornik K, Zeileis A (2006) Party: a laboratory for recursive part(y)itioning. $\mathrm{R}$ package version $0.9-0$. http://cran.stat.auckland.ac.nz/web/packages/party/ vignettes/party.pdf

Keefer ML, Peery CA, Heinrich MJ (2008) Temperaturemediated en route migration mortality and travel rates of endangered Snake River sockeye salmon. Ecol Freshw Fish 17:136-145

Kolok AS (1999) Interindividual variation in the prolonged locomotor performance of ectothermic vertebrates: a comparison of fish and herpetofaunal methodologies and a brief review of the recent fish literature. Can J Fish Aquat Sci 56:700-710

Liao JC (2007) A review of fish swimming mechanics and behaviour in altered flows. Phil Trans R Soc B 362: 1973-1993

Liaw A, Wiener M (2002) Classification and regression with random forest. $\mathrm{R}$ package version 0.9-0. http://cran.rproject.org/web/packages/randomForest/index.html

Macdonald JS (ed) (2000) Mortality during the migration of Fraser River sockeye salmon (Oncorhynchus nerka): a study of the effect of ocean and river environmental conditions in 1997. Can Tech Rep Fish Aquat Sci 2315. 
Department of Fisheries and Oceans, Burnaby, BC

Martins EG, Hinch SG, Patterson DA, Hague MJ and others (2011) Effects of river temperature and climate warming on stock-specific survival of adult migrating Fraser River sockeye salmon (Oncorhynchus nerka). Glob Change Biol 17:99-114

Ney JJ (1993) Bioenergetics modeling today: growing pains on the cutting edge. Trans Am Fish Soc 122:736-748

$>$ Poff NL, Zimmerman JKH (2010) Ecological responses to altered flow regimes: a literature review to inform the science and management of environmental flows. Freshw Biol 55:194-205

Pon LB, Hinch SG, Cooke SJ, Patterson DA, Farrell AP (2009) Physiological, energetic, and behavioural correlates of successful fishway passage of adult sockeye salmon Oncorhynchus nerka in the Seton River, British Columbia. J Fish Biol 74:1323-1336

Prasad AM, Iverson LR, Liaw A (2006) Newer classification and regression tree techniques: bagging and random forests for ecological prediction. Ecosystems 9:181-199

R Development Core Team (2010) R: a language and environment for statistical computing. R Foundation for Statistical Computing, Vienna. www.R-project.org/

Rand PS, Hinch SG (1998) Swim speeds and energy use of upriver-migrating sockeye salmon (Oncorhynchus nerka): simulating metabolic power and assessing risk of energy depletion. Can J Fish Aquat Sci 55:1832-1841

Scruton DA, Booth RK, Pennell CJ, Cubitt F, McKinley RS, Clarke KD (2007) Conventional and EMG telemetry studies of upstream migration and tailrace attraction of adult Atlantic salmon at a hydroelectric installation on the Exploits River, Newfoundland, Canada. Hydrobiologia 582:67-79

> Standen EM, Hinch SG, Healey MC, Farrell AP (2002) Energetics of upriver migrating adult pink (Oncorhynchus gorbuscha) and sockeye (O. nerka) salmon as assessed by EMG telemetry in the Fraser River Canyon, British Columbia. Can J Fish Aquat Sci 59:1809-1818

Strobl C, Boulesteix AL, Zeileis A, Hothorn T (2007) Bias in random forest variable importance measures: illustrations, sources and a solution. BMC Bioinformatics 8:25, doi:10.1186/1471-2105-8-25

Strobl C, Boulesteix AL, Kneib T, Augustin T, Zeileis A (2008) Conditional variable importance for random forests. BMC Bioinformatics 9:307, doi:10.1186/1471-2105-9-307

Sullivan GH, Hoefener C, Bolie VW (1963) Electronic systems for biological telemetry. In: Slater LE (ed) Biotelemetry: the use of telemetry in animal behaviour and physiology in relation to ecological problems. Pergamon Press, Oxford, p 83-106

Taylor MK, Cook KV, Hasler CT, Schmidt DC, Cooke S (2012) Behaviour and physiology of mountain whitefish (Prosopium williamsoni) relative to short-term changes in river flow. Ecol Freshw Fish 21:609-616

Trites AW, Beggs CW, Riddell B (1996) Status review of the Puntledge River summer Chinook. Draft report prepared for Fisheries and Oceans Canada by the Fisheries Centre at the University of British Columbia, Vancouver, BC. Available at: www.marinemammal.org/pdfs/trites_beggs 96.pdf

Appendix. Additional data on tagged Chinook salmon Oncorhynchus tshawytscha and their presence in different reaches of the Puntledge River, British Columbia, Canada

Table A1. Oncorhynchus tshawytscha. Information on the electromyogram (EMG)-tagged fish used in the study. Fish 1 to 11 were tagged in 2008, Fish 12 to 27 were tagged in 2007. Percentage of time recorded at each location (reach) is provided along with number of hourly periods for which each fish had EMG recordings. Reach abbreviations as in Fig. 1

\begin{tabular}{|c|c|c|c|c|c|c|c|c|c|}
\hline \multirow{2}{*}{$\begin{array}{l}\text { Fish } \\
\text { ID }\end{array}$} & \multirow{2}{*}{$\begin{array}{l}\text { 90th percentile } \\
\text { of EMG output }\end{array}$} & \multirow{2}{*}{$\begin{array}{l}\text { Number of } \\
\text { hourly periods }\end{array}$} & \multicolumn{7}{|c|}{ - Time spent in a reach $(\%)$} \\
\hline & & & $1(\mathrm{LH})$ & 2 (PHP) & 3 (ISP) & $4(\mathrm{SF})$ & $5(\mathrm{HW})$ & $6(\mathrm{NF})$ & $7(\mathrm{BP})$ \\
\hline 1 & 21 & 413 & 3.1 & 0 & 5.8 & 41.2 & 0.5 & 49.4 & 0 \\
\hline 2 & 23 & 377 & 0 & 0 & 2.7 & 8.2 & 2.7 & 54.4 & 32.0 \\
\hline 3 & 49 & 220 & 5.5 & 85.9 & 8.6 & 0 & 0 & 0 & 0 \\
\hline 4 & 20 & 338 & 3.6 & 0 & 6.8 & 10.7 & 1.8 & 71.5 & 5.6 \\
\hline 5 & 28 & 264 & 2.3 & 67.0 & 3.0 & 12.9 & 0 & 7.2 & 7.6 \\
\hline 6 & 25 & 319 & 0 & 0 & 16.3 & 27.0 & 0.6 & 56.1 & 0 \\
\hline 7 & 24 & 264 & 1.1 & 7.6 & 40.9 & 50.4 & 0 & 0 & 0 \\
\hline 8 & 24 & 356 & 2.8 & 5.6 & 2.8 & 25.6 & 25.8 & 24.4 & 13.0 \\
\hline 9 & 50 & 291 & 12.4 & 61.8 & 0 & 25.8 & 0 & 0 & 0 \\
\hline 10 & 25 & 247 & 0 & 17.0 & 5.3 & 35.2 & 0.4 & 32.8 & 9.3 \\
\hline 11 & 31 & 241 & 4.6 & 64.6 & 1.7 & 9.1 & 2.1 & 7.9 & 10 \\
\hline 12 & 41 & 314 & 0 & 0 & 37.3 & 62.7 & 0 & 0 & 0 \\
\hline 13 & 25 & 308 & 0 & 0 & 3.9 & 81.5 & 1.9 & 3.9 & 8.8 \\
\hline 14 & 23 & 263 & 0 & 0 & 4.6 & 77.1 & 0.8 & 11.8 & 5.7 \\
\hline 15 & 24 & 70 & 0 & 0 & 94.3 & 5.7 & 0 & 0 & 0 \\
\hline 16 & 34 & 183 & 2.2 & 1.1 & 7.7 & 89.0 & 0 & 0 & 0 \\
\hline 17 & 23 & 267 & 0 & 28.5 & 6.7 & 55.4 & 4.9 & 4.5 & 0 \\
\hline 18 & 33 & 178 & 0 & 12.4 & 15.2 & 55.0 & 10.7 & 6.7 & 0 \\
\hline 19 & 29 & 319 & 0 & 0 & 15.7 & 75.2 & 4.4 & 1.6 & 3.1 \\
\hline 20 & 35 & 185 & 0 & 17.3 & 54.1 & 28.6 & 0 & 0 & 0 \\
\hline 21 & 22 & 174 & 0 & 7.5 & 7.5 & 60.3 & 1.7 & 7.5 & 15.5 \\
\hline 22 & 24 & 501 & 0 & 0 & 1.2 & 97.6 & 0.4 & 0.8 & 0 \\
\hline 23 & 50 & 81 & 33.3 & 40.7 & 25.9 & 0 & 0 & 0 & 0 \\
\hline 24 & 40 & 344 & 0 & 23.3 & 2.9 & 56.1 & 0.6 & 9.3 & 7.8 \\
\hline 25 & 26 & 105 & 0 & 0 & 98.1 & 1.9 & 0 & 0 & 0 \\
\hline 26 & 36 & 21 & 0 & 0 & 100 & 0 & 0 & 0 & 0 \\
\hline 27 & 20 & 102 & 10.8 & 11.8 & 15.7 & 46.1 & 0 & 2.0 & 13.7 \\
\hline
\end{tabular}

